\title{
Promoting Independence among Children with Disabilities at the Milwaukee Center for Independence (MCFI)
}

\author{
Michael Quinn \\ Children's and Autism Programming, \\ Milwaukee Center for Independence, \\ Wisconsin, USA
}

Received: June 30, 2016; Accepted: August 03, 2016; Published: August 08, 2016

\section{Introduction}

The United Nations Convention on the Rights of Persons with Disabilities (UNCRPD) [1] formally and explicitly recognizes the importance of how to achieve independence for individuals with a disability. This encompasses individual autonomy, the opportunity to be actively involved in decision-making processes, and the opportunity to access the physical, social, economic and cultural environment [1]. To ensure independence is achieved, it is crucial that individuals have access to a range of opportunities and resources so that they can make meaningful choices and decisions about the management of their life and environment [2]. The Milwaukee Center for Independence (MCFI) is a nonprofit agency assisting individuals with a disability to live and work successfully in their communities. At MCFI, the concept of independence is reflected throughout the agencies many evidence-based programs and services. The purpose of this article is to describe how independence is fostered in children attending the School for Early Development and Achievement (SEDA), an affiliate of MCFI. Founded in 2002, SEDA provides early intervention services to at-risk children from grades $\mathrm{K} 4$ through $2^{\text {nd }}$, with a particular focus on children with early developmental disabilities. SEDA is a free public school chartered through the University of Wisconsin-Milwaukee. The intended audience for this article includes parents and families of children with early developmental disabilities, teachers, special educators, speech, occupational and physical therapists, donors and potential donors of non-profit organizations.

\section{Why does Independence Matter?}

In the United States, children with developmental disabilities represent a significant minority of the population. It is estimated that $15 \%$ of children have one or more developmental disabilities [3]. Examples of the most common developmental disabilities include Autism, Attention Deficit Hyperactivity Disorder (ADHD) and Intellectual Developmental Disorder. Disability stems from the interaction between impairments and attitudinal/environmental barriers [1]. Consequently, disability can compromise a child's functioning and development across various domains. For example, children with a disability are much less likely to be engaged in education, work and community which have of course social, family and economic implications [2]. Families and caretakers are also less likely to be fully engaged socially and

\section{Corresponding author:} Michael Quinn

Đmichael.quinn@mcfi.net

Director of Children's and Autism Programming, Milwaukee Center for Independence (MCFI), Harry \& Jeanette Weinberg Building, 2020 West Wells Street, Milwaukee, WI 53233, USA.

Tel: 414-459-3070

Citation: Quinn M. Promoting Independence among Children with Disabilities at the Milwaukee Center for Independence (MCFI). J Child Dev Disord. 2016, 2:3.

economically and are themselves more likely to be experiencing social isolation and poor health [2]. It is therefore evident that children with disabilities need access to a range of opportunities and resources to maximize their independence.

\section{School for Early Development and Achievement (SEDA)}

SEDA's mission is to increase developmental competencies and educational achievement of young children as a strong foundation for learning and success throughout their lives. As mentioned previously, to ensure independence is achieved, it is crucial that individuals have access to a range of opportunities and resources so that they can make meaningful choices and decisions about the management of their life and environment [2]. At SEDA, a multidisciplinary team comprising of teachers, special educators, speech, occupational and physical therapists work collaboratively to increase independence in children using evidence-based programs and practices. The following subsections of this article review some of the evidence-based strategies utilized by SEDA:

a) SEDA offers families support and resources from the first day their child is enrolled, giving them the tools they need to help students reach their highest levels of success. For 
example, if a student presents with speech and language difficulties, a crucial step for increasing independence is strengthening his/her ability to communicate. SEDA provides speech therapy intervention and treatment. The Picture Exchange Communication Program (PECS) is another approach utilized by SEDA's multidisciplinary team to foster independence and enhance communication in students who do not use speech as their primary means of communication. Using PECS, students are taught to communicate a need by exchanging an image.

b) Occupational therapy is also utilized to develop students' physical, sensory and motor skills functioning. Treatment can include stretching, strengthening, balance, functional training, support in reaching developmental motor milestones, accommodations for activities of daily living, and assistance in determining needs for seating and assistive devices [4].

c) Students learn to self-regulate behavior and mindfully engage in focused concentration. Research shows that self-regulated students are more engaged in their learning
[5] and they are more inclined to seek out advice [6] and information [7] and explore positive learning climates [8] compared to their peers who present with less regulation in school [5].

d) SEDA attains and maintains an inclusive learning environment where the voices of all students are heard and listed to. Listening to student voice increases youth independence, creates greater attachment to schools, and builds a range of skills and competencies, including learning to get along with others, planning complex projects, and public speaking $[8,9]$.

\section{Conclusion}

Independent skills are fundamentally important for all children, particularly those with a disability. In this brief but informative article, SEDA, an affiliate of MCFI, reflects its ability to foster independence in children with early developmental disabilities. This is achieved by a multidisciplinary team utilizing strategies informed by evidence-based research. Consequently, children are provided with a solid foundation to fulfill their potential. 


\section{References}

1 United Nations (2008) Convention on the Rights of Persons with Disabilities. Geneva: United Nations.

2 Stokes H, Turnbull M, Wyn J (2013) Young people with a disability: independence and opportunity. The University of Melbourne, Australia: Youth Research Centre.

3 Boyle CA, Boulet S, Schieve L, Cohen RA, Blumberg SJ, et al. (2011) Trends in the prevalence of developmental disabilities in US children, 1997-2008. Pediatrics 27: 1034-1042.

4 Bovid KM, Patel DR (2016) Orthopaedic considerations. In: Rubin IL, Merrick J, Greydanus DE, Patel DR (eds.) Health care for people with intellectual and developmental disabilities across a the life span. Switzerland: Springer, pp: 1109.
5 Zumbrunn S, Tadlock J, Roberts ED (2011) Encouraging self-regulated learning in the classroom: a review of the Literature. Virginia Commonwealth University: MERC.

6 Clarebout G, Horz H, Schnotz W (2010) The relations between selfregulation and the embedding of support in learning environments. Educ Technol Res Dev 58: 573-587.

7 de Bruin AB, Thiede KW, Camp G (2001) Generating keywords improves metacomprehension and self-regulation in elementary and middle school children. J Exp Child Psychol 109: 294-310.

8 Labuhn AS, Zimmerman BJ, Hasselhorn M (2010) Enhancing students' self-regulation and mathematics performance: The influence of feedback and self-evaluative standards. Metacogn Learn 5: 173-194.

9 Mitra D (2008) Student voice in school reform. Albany, New York: State University of New York Press, Albany. 